\title{
EDITORIAL
}

\section{Women on board: mind the (gender) gap}

\author{
Fabrizia Gelardi ${ }^{1,2} \cdot$ Noemi Gozzi $^{2}$
}

Published online: 23 June 2021

(c) The Author(s), under exclusive licence to Springer-Verlag GmbH Germany, part of Springer Nature 2021

The recognition of Hippocrates as the father of medicine is proved by several pieces of evidence, including the fact that the Declaration of Geneva [1] - the physician's pledge as a member of the medical profession-is a modern revised version of the Hippocratic Oath [2]. Changes from the original oath include, among others, "my colleagues will be my sisters and brothers," while in the original version was "my colleagues will be my brothers." Indeed, although women's involvement in healing activities was proved, Hippocratic physicians affirmed their medical authority through the "sōphrosunē," a Greek civic virtue proper of elite men [3], posing the basis for gender inequity in medicine.

After more than 2000 years, gender inequity persists in scientific research and academia; a phenomenon described as a "leaky pipeline" [4]. Surprisingly, this phenomenon is still present despite women empowerment in higher education. Indeed, gender distribution in higher education has been progressively overthrown over the last few decades. In the majority of member states of the Organization for Economic Co-operation and Development (OECD), men are underrepresented in tertiary education $[5,6]$. In STEM programs (science, technology, engineering, and mathematics), men currently outnumber women, while the majority of students enrolled in medical schools are women $[6,7]$.

Nonetheless, women inclusion failed in higher academic ranks. In Italy, just over 50\% of research fellows are women, but the female representation decreases progressively, climbing the career pyramid (47\% assistant professors, $38.4 \%$ associate professors, and $23.7 \%$ full professors) [8]. The low proportion of women in research and academic leadership

This article is part of the Topical Collection on Editorial

Fabrizia Gelardi

fabrizia.gelardi@humanitas.it

1 Department of Biomedical Sciences, Humanitas University, Via Rita Levi Montalcini 4, Pieve Emanuele, 20090 Milan, Italy

2 IRCCS Humanitas Research Hospital, Via Manzoni 56, Rozzano, 20089 Milan, Italy roles has been established as an issue in many fields, domains, and disciplines [3], including the nuclear medicine landscape [9, 10]. In 2020, Elsevier released a global report on the gender publication gap in research based on Scopus data. Although the last 5 years revealed a gender balance in the proportion of authors, worldwide, women performance is lower than men regardless of the research field in terms of authorship position, the number of publications, citations, collaborations, and grants awarded. Nonetheless, women's representation is more excellent among authors with a short publication history than men [11]. Furthermore, gender balance in the editorial staff of scientific journals is still far.

Women are strongly underrepresented in the editorial boards and editor-in-chief positions in most high-impact radiology journals $[10,12]$. Therefore, we explored gender representation in the editorial boards of the European Association of Nuclear Medicine (EANM) family of Journals.

We collected data from the five journals of the EJNMMI family-European Journal of Nuclear Medicine and Molecular Imaging (EJNMMI), EJNMMI Research, EJNMMI Physics, EJNMMI Radiopharmacy and Chemistry, and EJNMMI Hybrid. Editors-in-chief and editorial boards' gender, $\mathrm{H}$-indexes, publications, and citations data were collected. Editors-in-chief, associate editors, and editorial boards' names and affiliations were obtained from the official journal website on June 8, 2021. Gender was established by checking each member on institutional websites. H-indexes, 5-year H-indexes (from 2016 to 2021), and number of publications and citations were obtained using pybliometrics python interface for Scopus API. For each journal, the percentage of gender representations were calculated. Shapiro-Wilk was performed to test variables' normal distribution. A two-sample Wilcoxon rank-sum (Mann-Whitney) test was performed to compare two groups. Statistical analyses were conducted with STATA (STATA version 16.1 StataCorp LP, College Station, TX, USA). P-value $\leq 0.01$ was considered for statistical significance.

Figure 1 shows a schematic representation of our results.

Overall, we found a substantial gender gap, regardless of the editorial board's rank (i.e., editor-in-chief, associated 


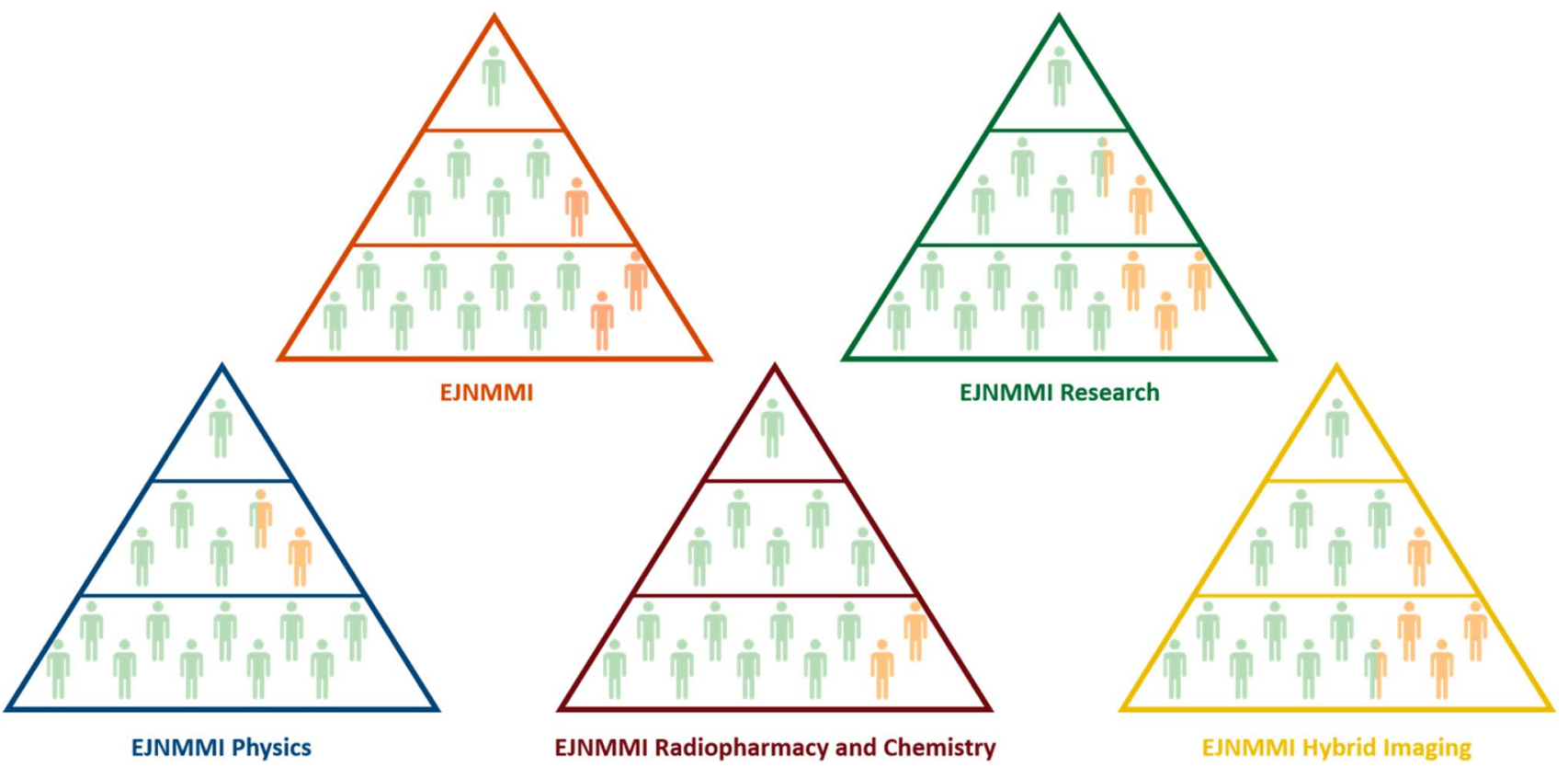

Fig. 1 Males/females percentages for EJNMMI, EJNMMI Research, EJNMMI Physics, EJNMMI Radiopharmacy and Chemistry, and EJNMMI Hybrid Imaging. Males are represented in green, and

editors, and editorial board members). Editors-in-chief are all men and female members within the associated editors are a minority. The editorial board ranged from a minimum of 6 out of 30 and $20 \%$ in the EJNMMI Physics to a maximum of 14 out of 44 and 32\% in EJNMMI Hybrid Imaging, respectively.

Considering the $\mathrm{H}$-indexes, the two groups (female vs male) were significantly different for all journals except EJNMMI Hybrid Imaging (Fig. 2). These findings were consistent with data previously reported in radiology journals females in yellow. Approximate percentages are computed separately for editor-in-chief (top), associated editors (middle), and editorial boards (bottom)

$[10,12]$. Thus, publishing imbalance may be due to differences in professional opportunities by gender. Several hypotheses explain the fastest career advancement of men in achieving senior academic positions and consequently a higher publication performance. Among others, gender stereotypes, career interruptions due to maternity leaves, and the traditional social structure establish the woman as the primary referent for family and household duties [13-15]. Furthermore, the Global Gender Gap Report, published in 2021 by the World Economic Forum, claimed that the
Fig. 2 Median 5 years (5y) and $\mathrm{H}$-index of females $(\mathrm{F})$ and males (M) for the EJNMMI Journal Family

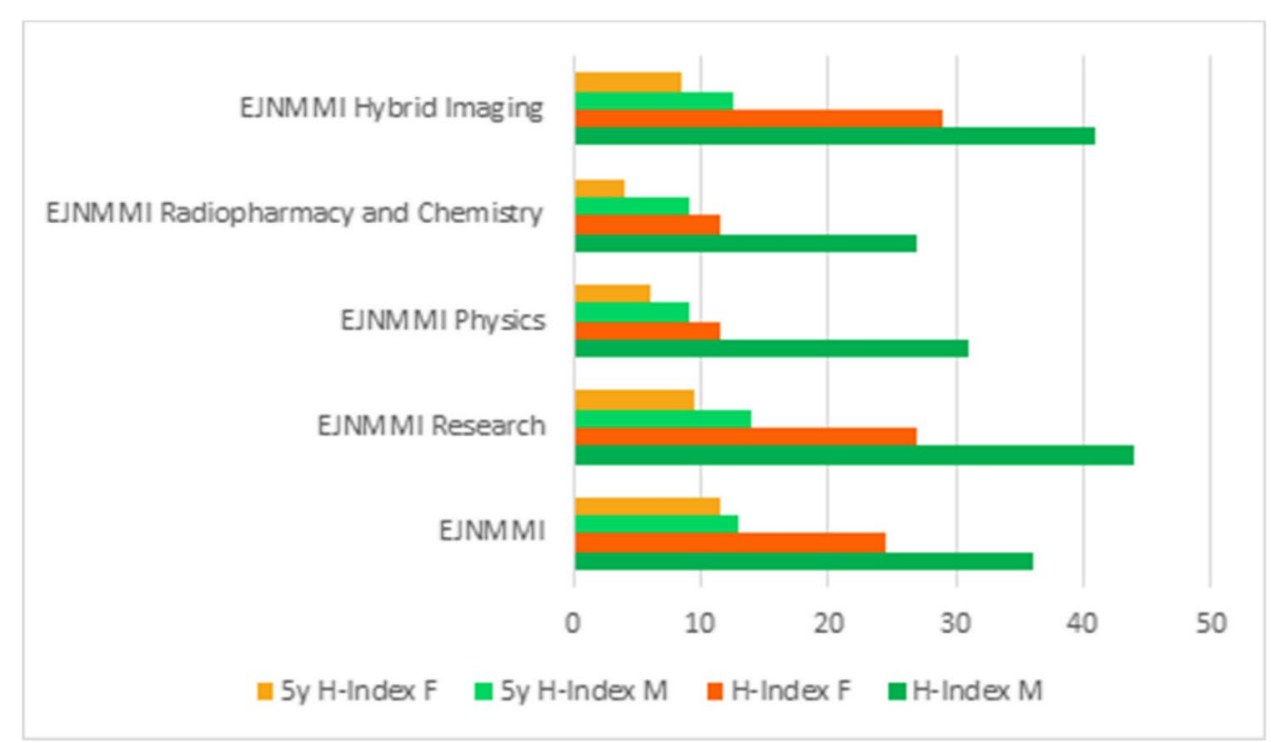


COVID-19 pandemic had worsened the gender gap even more [16]. A study published in 2020 revealed that female employment was around $44 \%$ but decreased around $20 \%$ for executive positions and to only 5.8\% for CEO positions in Standard and Poor's (S\&P) companies in the USA [17]. Similarly, in Europe, less than $10 \%$ of CEOs are women [18]. It should be acknowledged that the incomes do not justify this gender gap: companies with female CEOs or CFOs have better performance and are more profitable [19, 20]. Significant differences can also be found in the employment rate: in 2020 in Europe, the employment rate had a gender gap of 11.7 percentage points (pp) and is in favor of men for all education levels; thus, it cannot be justified by a different level of education [21].

On these grounds, publishing indicators such as H-index, number of publications and citations may not correctly reflect research efforts in both genders. H-index adjustment based on career age, periods of research inactivity due to maternity leave, and exclusions of self-citations (as male researchers are more prone to self-cite than women [22]) have been proposed to overcome gender biases in research impact [23]. Therefore, it was not surprising that statistics greatly improved (4/5 journals-EJNMMI, EJNMMI Research, EJNMMI Hybrid Imaging, EJNMMI Radiopharmacy and Chemistry - did not show any significant difference between the two groups) when considering the 5-year $\mathrm{H}$-index. Indeed, our data confirmed a gender gap even in the EJNMMI Journal Family editorial board composition, and it is our opinion that it is time to move beyond detailing the issue. Therefore, we present some suggestions:

(1) Promote improvements in contemporary society, primarily in the management of caring and household. The perception of the roles assigned to men and women must change, especially in families with children. The COVID-19 pandemic has further highlighted how far we are from true gender equality. Indeed, during the COVID-19 outbreak, there has been a dramatic drop in academic submissions by women [13] due to an increased burden of unpaid care work at home.

(2) The introduction of specific initiatives such as the Marie Curie Fellowship Programme [24] and the EANM Women Empowerment [25] is urgent to promote and support women's leadership. However, as defined at point 1 , these activities may be at odds with daily household life, possibly becoming a challenge more than an opportunity.

(3) Introduce publishing performance indicators that faithfully represent the quality of researchers without being biased and prone to advantage men. The $\mathrm{H}$-index of the last 5 years has already shown improvements compared to traditional metrics.
However, a faithful index should include career age and interruptions due to maternity. This has to be followed by a reduction of the gender gap between women and men in the editorial boards and associated editors. The comparison between the $\mathrm{H}$-index and $\mathrm{H}$-index from the last 5 years showed a positive trend of the success of women in research and despite the obstacles to women's growth in academia. This trend is expected to continue in the next few years, eventually reaching a turning point. Furthermore, if a new faithful index will be introduced, we expect this turning point to be even closer in time.

(4) Appoint women for competitive roles, such as editors-in-chief. Several studies have demonstrated how companies with females in essential roles are more productive and performant $[19,20]$. We believe a similar scenario could be reflected even in scientific research and journals.

Gender equality is still a dream even though there are no valid and sufficient reasons to explain this gap. We strongly believe that radical changes are necessary also in the organizational framework of scientific research and academia. Reducing the gender gap in journals will bring significant benefits; gain competitive, organized, challenged researchers; and bring various ideas, views, and approaches that will improve the scientific world.

\section{Declarations}

Ethics approval Institutional Review Board approval was not required because the paper is an Editorial.

Informed consent Not applicable.

Conflict of interest The authors declare no competing interests.

\section{References}

1. "Declaration of Geneva," Medical Journal of Australia, 1973. https://www.wma.net/policies-post/wma-declaration-ofgeneva/. Accessed 11 Jun 2021.

2. Miller HW and Edelstein L. The Hippocratic Oath. Text, translation and interpretation, vol. 38, no. 1. Baltimore: The Johns Hopkins Press., 1944.

3. Innes A and Hons BA, "Gender and Healing in the Hippocratic Corpus," 2012.

4. Pell AN. Fixing the leaky pipeline: women scientists in academia. J Anim Sci. 1996;74(11):2843-8. https://doi.org/10. 2527/1996.74112843x. 
5. Stoet G, Geary DC. Gender differences in the pathways to higher education. Proc Natl Acad Sci U S A. 2020;117(25):14073-6. https://doi.org/10.1073/pnas.2002861117.

6. UNESCO, "Women in higher education : has the female advantage put an end to gender inequalities ?," 2021. https://www.iesalc. unesco.org/en/wp-content/uploads/2021/03/Women-Report8032021.pdf. Accessed Jun 082021.

7. "Graduates of U.S. Medical schools by sex, academic years 1980-1981 through 2017-2018. Association of American Medical Colleges.https://www.aamc.org/download/493700/data/facts datachart4.pdf."

8. MIUR, "Focus - Le carriere femminili in ambito accademico," 2019. http://ustat.miur.it/media/1155/focus-carriere-femminiliuniversità.pdf. Accessed 08 Jun 2021.

9. Ekmekcioglu O, Evangelista L and Kunikowska J. "Women in nuclear medicine.," European journal of nuclear medicine and molecular imaging. Germany, May 2021, https://doi.org/10.1007/ s00259-021-05418-9.

10. Jalilianhasanpour R, Charkhchi P, Mirbolouk M, Yousem DM. Underrepresentation of women on radiology editorial boards. J Am Coll Radiol. 2019;16(1):115-20. https://doi.org/10.1016/j. jacr.2018.08.017.

11. de Kleijn et al M. "The researcher journey through a gender lens: an examination of research participation, career progression and perceptions across the globe," 2020. www.elsevier.com/genderreport. Accessed 08 Jun 2021.

12. Piper M, Mueller AC, Karam SD. The interplay between cancer associated fibroblasts and immune cells in the context of radiation therapy. Mol Carcinog. 2020;59(7):754-65. https://doi.org/ $10.1002 / \mathrm{mc} .23205$.

13. Upthegrove R, de Cates A, Shuttleworth A, Tracy DK, Broome MR, Lingford-Hughes A. Gender equality in academic publishing: action from the BJPsych. Br J Psychiatry. 2021;218(3):128-130. https://doi.org/10.1192/bjp.2020.192.

14. Teelken C, Taminiau Y, Rosenmöller C. Career mobility from associate to full professor in academia: micro-political practices and implicit gender stereotypes. Stud High Educ. 2021;46(4):83650. https://doi.org/10.1080/03075079.2019.1655725.

15. Miller CC. "Young men embrace gender equality, but they still don't vacuum," The New York Times, 2020. https://www.nytimes. com/2020/02/11/upshot/gender-roles-housework.html?referringS ource $=$ articleShare. Accessed 11 Jun 2021.
16. World Economic Forum, "Global gender gap report 2021," The World Economic Forum, 2021. https://www.weforum.org/repor ts/global-gender-gap-report-2021. Accessed 08 Jun 2021.

17. Catalyst, "Pyramid: women in S\&P 500 companies," Catalyst, 2015. http://www.catalyst.org/knowledge/women-sp-500-compa nies. Accessed 08 Jun 2021.

18. European Commission, "The gender pay gap situation in the EU," Eu, 2018. https://ec.europa.eu/info/policies/justice-and-fundamental-rights/gender-equality/equal-pay/gender-pay-gap-situation-eu_ en. Accessed 08 Jun 2021.

19. Sandberg DJ. "When women lead, firms win," 2019. www.spglo bal.com. Accessed 08 Jun 2021.

20. “Gender employment gap by education level in Q3 2020." https:// ec.europa.eu/eurostat/en/web/products-eurostat-news/-/EDN20210305-1. Accessed 08 Jun 2021.

21. Castrillon C. "Why women-led companies are better for employees," Forbes, 2019. https://www.forbes.com/sites/carolinecastril lon/2019/03/24/why-women-led-companies-are-better-for-emplo yees/?sh=29175c0c3264. Accessed 08 Jun 2021.

22. King MM, Bergstrom CT, Correll SJ, Jacquet J, West JD. Men set their own cites high: gender and self-citation across fields and over time. Socius Sociol Res a Dyn World. 2017;3:237802311773890. https://doi.org/10.1177/2378023117738903.

23. Cameron EZ, White AM, Gray ME. Solving the productivity and impact puzzle: do men outperform women, or are metrics biased? Bioscience. 2016;66(3):245-52. https://doi.org/10.1093/biosci/ biv173.

24. "IAEA Launches Marie Skłodowska-Curie Fellowship Programme to Push for More Women in Nuclear." https://www.iaea. org/newscenter/pressreleases/iaea-launches-marie-sklodowskacurie-fellowship-programme-to-push-for-more-women-in-nucle ar. Accessed 20 Apr 2021.

25. “EANM women's empowerment." https://www.eanm.org/about/ organs/womensempowerment/. Accessed 12 Jun 2021.

Publisher's note Springer Nature remains neutral with regard to jurisdictional claims in published maps and institutional affiliations. 